LETTER TO JMG

\title{
Mutations of the mitochondrial ND1 gene as a cause of MELAS
}

\author{
D M Kirby, R McFarland, A Ohtake, C Dunning, M T Ryan, C Wilson, D Ketteridge, D M Turnbull, \\ D R Thorburn, R W Taylor
}

C omplex I is the largest of the mitochondrial respiratory chain enzyme complexes, consisting of at least 46 subunits, seven of which are encoded by mtDNA. Deficiency of complex I is the most common respiratory chain defect, and can be caused by mutations in both nuclear and mtDNA encoded genes. It has a wide range of clinical presentations, from lethal infantile mitochondrial disease to isolated myopathy. ${ }^{1-3}$ Mitochondrial encephalopathy, lactic acidosis and stroke-like episodes (MELAS) is one of the syndromes associated with complex I deficiency and in approximately $80 \%$ of cases is caused by a mutation, $3243 \mathrm{~A} \rightarrow \mathrm{G}$, in the mitochondrial tRNA ${ }^{\mathrm{Leu}(\mathrm{UUR})}$ gene (MTTL1). Other mutations in MTTL1 and other transfer RNA genes (MTTF, MTTV, MTTQ) account for most of the remainder of cases. ${ }^{4}$ However, a number of mutations in the mitochondrial MTND subunit genes of complex I have also been reported to cause MELAS, most notably in $M T N D 5^{5}$ and to a lesser extent in MTND6. ${ }^{6}$

In stark contrast, there are presently no mutations in the MTNDl subunit gene associated with MELAS. There are several mutations in MTND1 associated with Leber's hereditary optic neuropathy (LHON) which may be pathogenic, but only one, the $3460 \mathrm{G} \rightarrow \mathrm{A}$ mutation, that has robust evidence, including cell biology studies, for pathogenicity..$^{7-9}$ Here we report three unrelated patients with MELAS and isolated complex I deficiency in skeletal muscle and cultured fibroblasts due to previously unreported mutations in the MTNDl gene. Evidence confirming the pathogenic nature of these mutations includes data from cell fusion experiments and blue native polyacrylamide gel electrophoresis (BNPAGE), the latter confirming a crucial role for the NDl subunit in the assembly of complex I holoenzyme. ${ }^{10}$

\section{PATIENTS}

\section{Patient 1}

Patient 1 , a white male, presented at 4 years of age with a 3 month history of increasing tiredness, clumsiness, frequent falls, and weakness of his left side. On examination he had increased tone and brisk reflexes in his left leg and walked with a hemiplegic gait. Magnetic resonance imaging (MRI) revealed lesions of the right lentiform and caudate nuclei. He made a partial recovery, but at 7 years of age presented with right sided facial twitching and speech difficulties. EEG suggested focal seizures, and MRI revealed new lesions of the right thalamus, left basal ganglia, and bifrontal cortical regions. Magnetic resonance spectroscopy revealed increased levels of lactate in these areas. CSF and blood lactate levels were $2.7 \mathrm{mmol} / \mathrm{l}$ and $1.3 \mathrm{mmol} / \mathrm{l}$ respectively (normal $<2.5 \mathrm{mmol} / \mathrm{l}$ for both). Skeletal muscle histology and enzyme histochemistry were normal, but electron microscopy indicated focal subsarcolemmal accumulation of mitochondria. The seizures resolved over 6 months. At 9 years of age he had a period of lethargy, slurred speech, and relatively poor functioning lasting 2 months. MRI revealed extension of the

\section{Key points}

- Mitochondrial encephalopathy, lactic acidosis, and stroke-like episodes (MELAS) is one of many clinical presentations associated with mutations in mitochondrial DNA (mtDNA) and a biochemical deficiency of respiratory chain complex I. While the 'common' $3243 A \rightarrow G$ mutation in the mitochondrial tRNA ${ }^{\text {Leu(UUR) }}$ (MTTL1) gene is detected in approximately $80 \%$ of patients with MELAS, the aetiology of the remaining $20 \%$ is heterogeneous, with different causative mutations occurring in $M T T L 1$, other mitochondrial tRNA (mt-tRNA) genes, and the MTND genes encoding subunits of complex $I$.

- We report three unrelated patients with MELAS in whom the 3243A $\rightarrow G$ mutation could not be detected, but who expressed a specific deficiency of complex I activity in both skeletal muscle and cultured fibroblasts. Targeted sequencing of mt-tRNA and MTND genes revealed that each patient harboured a different novel mutation in the MTND1 subunit gene of complex I $(3697 \mathrm{G} \rightarrow \mathrm{A}, 3946 \mathrm{G} \rightarrow \mathrm{A}$, and $3949 \mathrm{~T} \rightarrow \mathrm{C}$ ), each of which predicted an amino acid change. The failure to restore complex I activity upon fusion of patient cells with a cell line lacking mtDNA ( $\rho^{0}$ cells) confirmed pathogenicity for each of these mutations, all of which appear to perturb the assembly or turnover of complex I.

- Our finding of three novel mutations in the MTND1 gene causing MELAS is supportive of recent papers highlighting the importance of mtDNA mutations in the aetiology of childhood respiratory chain complex I deficiency and underlines the importance of a cohesive diagnostic strategy where molecular genetic investigations are shaped by the biochemical and histological findings.

lesions in the left basal ganglia and right frontal cortex. He has had no further acute episodes and at 10 years old he walks independently but requires a wheelchair for long distances. He has retained normal intelligence and there is no family history of note. On examination he has no cranial

Abbreviations: BN-PAGE, blue native polyacrylamide gel electrophoresis; CS, citrate synthase; CT, computed tomography; $L H O N$, Leber's hereditary optic neuropathy; MELAS, mitochondrial encephalopathy, lactic acidosis, and stroke-like episodes; MRI, magnetic resonance imaging; mtDNA, mitochondrial DNA; mt-tRNA, mitochondrial transfer RNA; RFLP, restriction fragment length polymorphism 
nerve signs and normal proximal power, but increased tone and brisk reflexes, especially in the lower limbs.

\section{Patient 2}

Patient 2, a white female, had normal developmental milestones until 5 years of age, when anxiety issues and schooling difficulties became evident. From 11 years of age she developed hearing problems, and high tone deafness was confirmed at when she was 14 years old. She presented at 14 years of age with frontal headaches, vomiting, and multiple left sided focal seizures, which became generalised over a 24 hour period. MRI and computed tomography (CT) of the head showed a right parietal lobe 'watershed' infarct, which showed some progression 7 days after the onset of seizures. Subsequent MRI and CT scans revealed further ischaemic areas in both occipital regions, and in the parietal, temporal, and frontal lobes. CSF and plasma lactate levels were elevated at $10.3 \mathrm{mmol} / \mathrm{l}$ and at $3.5 \mathrm{mmol} / \mathrm{l}$ respectively. Skeletal muscle biopsy was normal on both light and electron microscopy. Recurrent strokes complicated by seizures, episodes of cortical blindness of variable completeness, and other neurological deficits have occurred, leaving her with a moderate intellectual disability. A maternal half sister and full sister are reported to tire easily, as does her mother, who also suffers from high tone deafness and mild glucose intolerance.

\section{Patient 3}

This male patient of Chinese origin presented at 14 years of age with a short history of left sided upper limb focal seizures. The EEG showed focal spike and slow wave discharges over the right parasagittal region. A few months later, he presented with headache and blurred vision. On examination he had a left homonymous hemianopia with macular sparing, and MRI showed lesions in the right occipital and posterior frontal cortex. His visual problems resolved, but over the following year he had episodes of altered sensation in his limbs. A further MRI showed new T2 hyperintensity lesions in the anterior aspect of the left occipital lobe, the medial right parietal cortex, and the anterior frontal cortex. The basal ganglia were not affected. His CSF and plasma lactate levels were $3.4 \mathrm{mmol} / \mathrm{l}$ and $3.0 \mathrm{mmol} / \mathrm{l}$ respectively. Skeletal muscle enzyme histochemistry showed subsarcolemmal accumulations of mitochondria and EM revealed a moderately increased number of large, abnormally shaped mitochondria with abnormal cristae and excess lipid. At 16 years of age he has normal intelligence and little of note on examination. He has regular episodes of focal left hand seizures that are difficult to control but have not generalised. Medications include carbamazepine, coenzyme $\mathrm{Q}_{10}$, riboflavin, and vitamin $\mathrm{C}$. His mother and an older sister suffer from migraine, otherwise there is no family history of note.

\section{METHODS \\ Biochemistry}

The activities of the individual respiratory chain complexes and the mitochondrial matrix marker enzyme citrate synthase were measured in skeletal muscle homogenates and mitochondrial fractions isolated from cultured cells as described previously. ${ }^{21}$

\section{m+DNA analysis}

Total DNA was extracted from tissues, cultured cells, urine sediment, and blood by standard procedures. Manual sequencing of the MTTL1 gene was performed using a ThermoSequenase radiolabeled terminator cycle sequencing kit (USB Corporation, Cleveland, OH, USA). For automated sequencing, the coding region of the mitochondrial genome was amplified using a series of overlapping oligonucleotide primer pairs and sequenced with a BigDye terminator cycle sequencing kit as described previously. ${ }^{12}$ Sequence data were analysed using Navigator and Factura software (Applied Biosystems, Warrington, UK) and compared to the revised Cambridge reference sequence of human mtDNA. ${ }^{13}$

\section{Quantification of mtDNA heteroplasmy}

Putative pathogenic sequence variants in tissues and cells from the patients and other family members were further investigated by last hot cycle PCR-restriction fragment length polymorphism (RFLP) analysis. Details of the oligonucleotide primers and restriction endonucleases used for each of the patients are provided in table 1 , along with the expected fragment sizes after digestion. The relative proportions of normal and mutated mtDNA genomes in different tissues were determined by the addition of $5 \mu \mathrm{Ci}\left[\alpha-{ }^{32} \mathrm{P}\right]$-dCTP $(3000 \mathrm{Ci} / \mathrm{mmol})$ prior to the last cycle of the PCR. Labelled products were digested with $10 \mathrm{U}$ of the appropriate restriction endonuclease (table 1), separated through a $12 \%$ non-denaturing polyacrylamide gel, and the radioactivity in each fragment quantified using ImageQuant software (Molecular Dynamics, Sunnyvale, CA, USA).

\section{Cell biology studies}

Cells were cultured in Dulbecco's modified Eagle's medium (JRH Biosciences, Lenexa, KS, USA), supplemented with 10\% fetal calf serum (JRH Biosciences) and $50 \mu \mathrm{mol} / \mathrm{l}$ uridine.

\section{Generation of antibiotic resistant cell lines}

G418 resistance and increased growth potential were conferred on a control fibroblast cell line and the 143BTK $\rho^{0}$ osteosarcoma cell line as described. ${ }^{14}$ Similarly, patient fibroblasts were transfected with Hygromycin B resistance and SV40 $\mathrm{T}$ antigen via pGKHygT, derived from the pGKHyg plasmid (gift of $\mathrm{Dr} R$ Saffery). Antibiotic resistant clones were isolated after selection with Hygromycin B (Roche Diagnostics Australia, Castle Hill, NSW, Australia).

\section{Generation of hybrids}

Two cell lines with different antibiotic resistance were co-cultured until confluent and fused using polyethylene glycol (PEG 1500, 50\% solution in $15 \mathrm{mmol} / \mathrm{l}$ HEPES; Roche Diagnostics Australia, Castle Hill, NSW, Australia). Heterokaryons were selected in medium containing both G4l8 $(200 \mu \mathrm{g} / \mathrm{ml})$ and hygromycin B $(100 \mu \mathrm{g} / \mathrm{ml})$. Dual antibiotic resistant hybrids were passaged in the selective medium at least twice after the parental and "self self" fused cells had died (usually after 5-10 days) before analysis of complex I activity. Cell fusion experiments and complex I enzyme analysis were performed in duplicate.

\section{Protein analysis}

The amount and size of assembled complex I was studied by BN-PAGE and immunoblotting using mitochondria isolated from primary fibroblast cell lines from patients 1, 2, and 3 as described previously. ${ }^{14} 15$

\section{RESULTS}

\section{Biochemistry}

Respiratory chain enzymes in skeletal muscle homogenates and cultured skin fibroblasts from each patient were consistent with an isolated defect of complex I according to the criteria described previously ${ }^{2}$ (table 2). For patient 1, complex I activity in muscle was not clearly deficient when expressed relative to protein or as a ratio to the mitochondrial matrix enzyme citrate synthase (CS), but was deficient when expressed relative to complex II (23\% of control mean). All 
Table 1 PCR-RFLP analysis of putative pathogenic MTND1 gene mutations in the three patients

\begin{tabular}{|c|c|c|c|c|}
\hline $\begin{array}{l}\text { Sequence } \\
\text { variant }\end{array}$ & Primers & Primer sequences $\left(5^{\prime}\right.$ to $\left.3^{\prime}\right)$ & $\begin{array}{l}\text { Restriction } \\
\text { enzyme }\end{array}$ & Expected fragment sizes (bp) \\
\hline $\begin{array}{l}\text { Patient } 1 \\
(3697 G \rightarrow A) \\
\text { Patient } 2 \\
(3946 G \rightarrow A) \\
\text { Patient } 3 \\
(3949 T \rightarrow C)\end{array}$ & $\begin{array}{l}\text { L3607-3627 } \\
\text { H3795-37776 } \\
\text { L3875-3894 } \\
\text { H4031-4011 } \\
\text { L3928-3948 } \\
\text { H4113-4094 }\end{array}$ & $\begin{array}{l}\text { GGCCTCCTATTIATTCTAGCC } \\
\text { GGAGAGGTTAAAGGAGCCAC } \\
\text { TAGCAGAGACCAACCGAACC } \\
\text { AAGATTGTAGTGGTGAGGGTG } \\
\text { tgtaaaacgacggccagtGTCTCAGGCTTCAACATCGTA } \\
\text { caggaaacagctatgaccCAGGGAGGTTAGAAGTACGG }\end{array}$ & $\begin{array}{l}\text { Bcll } \\
\text { Taql } \\
\text { Rsal }\end{array}$ & $\begin{array}{l}\text { Wildtype: } 189 \rightarrow 137+52 \\
\text { 3697G } \rightarrow \text { A: } 189 \rightarrow 103+52+34 \\
\text { Wildtype: } 157 \rightarrow 87+43+27 \\
\text { 3946G } \rightarrow \text { A: } 157 \rightarrow 130+27 \\
\text { Wildtype: } 222 \rightarrow 188+34 \\
\text { 3949T } \rightarrow \text { C: } 222 \rightarrow 150+38+34\end{array}$ \\
\hline
\end{tabular}

Details of the oligonucleotide primers, restriction endonucleases, and expected fragment sizes following enzyme digestion are given.

For patient 3, primers have additional M13 sequence (shown in lower case), while mismatch nucleotides are in bold.

respiratory chain enzymes measured except complex I were $180-280 \%$ of control means relative to CS in that sample, reflecting mitochondrial proliferation.

\section{Identification of pathogenic mutations}

Sequence analysis of the MTTL1 gene was normal for all three patients. This prompted sequencing of the ND and mt-tRNA coding regions of the mitochondrial genome. In addition to recognised polymorphisms, each patient had a number of changes that had not been reported previously in public databases $^{16}{ }^{17}$ (see also http://www.genpat.uu.se/mtDB/polysites. html). While many changes were synonymous or occurred in non-conserved regions of the genome, each patient had a different heteroplasmic mutation, predicted to change a conserved amino acid of the MTNDl gene. These mutations, $(3697 \mathrm{G} \rightarrow \mathrm{A} \quad(\mathrm{G} 131 \mathrm{~S}), \quad 3946 \mathrm{G} \rightarrow \mathrm{A} \quad(\mathrm{E} 214 \mathrm{~K})$ and $3949 \mathrm{~T} \rightarrow \mathrm{C}$ $(\mathrm{Y} 215 \mathrm{H}))$, were therefore potentially pathogenic and entirely consistent with a resultant complex I deficiency.

PCR-RFLP assays were developed for each of these sequence variants, and mutant loads were determined by last cycle hot PCR (table 1). Patient 1 had $80 \%$ and $79 \%$ of the $3697 \mathrm{G} \rightarrow \mathrm{A}$ mutation in skeletal muscle and fibroblasts respectively. The mutant load was $3 \%$ in blood from his mother, but no mutation was detected in blood from his two sisters (fig 1A), two maternal aunts, maternal uncle, or maternal grandmother (not shown), all of whom were asymptomatic.

Patient 2 harboured somewhat lower mutant load, with $60 \%$ of the $3946 \mathrm{G} \rightarrow$ A mutation in muscle, $45 \%$ in fibroblasts, and $37 \%$ in blood. No mutation was detected in blood or urine sediment from her mother, while 3\% mutant load was detected in urine sediment from her sister (fig 1B), implying that although the mother harbours the mutation in ovarian tissue, it may be selected against in mitotic tissues as previously reported for the $3243 \mathrm{~A} \rightarrow \mathrm{G}$ MTTL1 mutation. ${ }^{18}$

Patient 3 had $93 \%$ of the $3949 \mathrm{~T} \rightarrow \mathrm{C}$ mutation in muscle, $88 \%$ in fibroblasts, and $45 \%$ in blood. Thus it appears likely that the $3949 \mathrm{~T} \rightarrow \mathrm{C}$ mutation is also selected against in blood.
No mutation was detected in blood from his asymptomatic mother and two brothers (fig IC).

We also used PCR-RFLP analysis to screen for the $3697 \mathrm{G} \rightarrow \mathrm{A}, \quad 3946 \mathrm{G} \rightarrow \mathrm{A}$, and $3949 \mathrm{~T} \rightarrow \mathrm{C}$ mutations in 68 complex I deficient paediatric patients in whom no causative mutation had been found. None of these mutations was detected in these patients.

\section{Cell biology studies}

When fibroblasts from a complex I deficient patient with a presumed nuclear DNA defect were fused with the $143 \mathrm{BTK}^{-} \rho^{0}$ osteosarcoma cell line, the hybrids showed restoration of complex I activity. However, fusion of fibroblasts from the three patients reported here and the 143BTK $\rho^{0}$ osteosarcoma cell line failed to restore complex I activity (fig 2 ). As the $\rho^{0}$ cell line contains no mtDNA, lack of phenotypic rescue in the hybrids indicates that the nucleus of the $\rho^{0}$ cell line is unable to correct the complex I defect. These results imply that the complex I defect in the three patient cell lines is of mtDNA origin ${ }^{19}{ }^{20}$ and confirm that the novel mutations described here are causative.

\section{Protein studies}

Analysis of the intact complex after separation by BN-PAGE with an antibody to the $39 \mathrm{kDa}$ subunit of complex I revealed dramatically reduced levels of fully assembled complex I for each of the three patients $(25 \%$ for $3697 \mathrm{G} \rightarrow \mathrm{A}, 11 \%$ for $3946 \mathrm{G} \rightarrow \mathrm{A}$, and $12 \%$ for $3949 \mathrm{~T} \rightarrow \mathrm{C}$ ) compared to a control fibroblast cell line (fig 3).

\section{DISCUSSION}

All three patients presented with a classical MELAS phenotype and suggestive family history, but without evidence of $3243 \mathrm{~A} \rightarrow \mathrm{G}$ or other mutations in the MTTL1 gene. The finding of an isolated complex I deficiency, with normal complex IV/CS and complex IV/complex II ratios in skeletal muscle, led us to investigate a possible mtDNA mutation as the cause of the clinical disease. The elevation of

Table 2 Residual complex I activities in skeletal muscle homogenates and isolated fibroblast mitochondria

\begin{tabular}{|c|c|c|c|c|c|c|}
\hline \multirow[b]{3}{*}{ Complex } & \multicolumn{6}{|c|}{$\%$ Activity (observed range for controls) } \\
\hline & \multicolumn{2}{|l|}{ Patient 1} & \multicolumn{2}{|l|}{ Patient 2} & \multicolumn{2}{|l|}{ Patient 3} \\
\hline & Muscle & Fibroblasts & Muscle & Fibroblasts & Muscle & Fibroblasts \\
\hline Col & $68(43-204)$ & $18(46-191)$ & $2(43-204)$ & $27(46-191)$ & $27(43-204)$ & $28(46-191)$ \\
\hline Col/CS & $60(36-167)$ & $35(50-145)$ & $2(36-167)$ & $34(50-145)$ & $19(36-167)$ & $24(50-145)$ \\
\hline Col/Coll & $23(51-153)$ & $19(46-169)$ & $2(51-153)$ & $14(46-169)$ & $11(51-153)$ & $13(46-169)$ \\
\hline
\end{tabular}

All assays were performed in duplicate.

Complex I (Col) activity was expressed as percentage of the mean of controls (for skeletal muscle homogenates, $\mathrm{n}=16$, mean activity $44 \mathrm{nmol} / \mathrm{min} / \mathrm{mg}$, observed range 19-90; for fibroblast mitochondria, $n=35$, mean activity $74 \mathrm{nmol} / \mathrm{min} / \mathrm{mg}$, observed range 34-141) and relative to the activity of citrate synthase (Col/CS) and complex II (Col/Coll). ${ }^{2}$ 


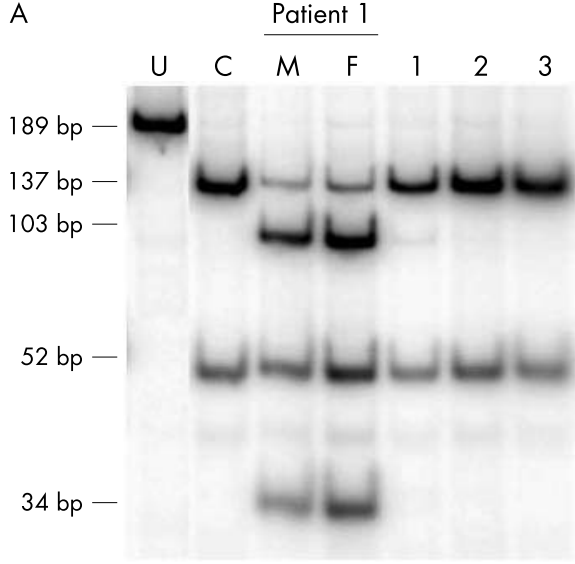

B
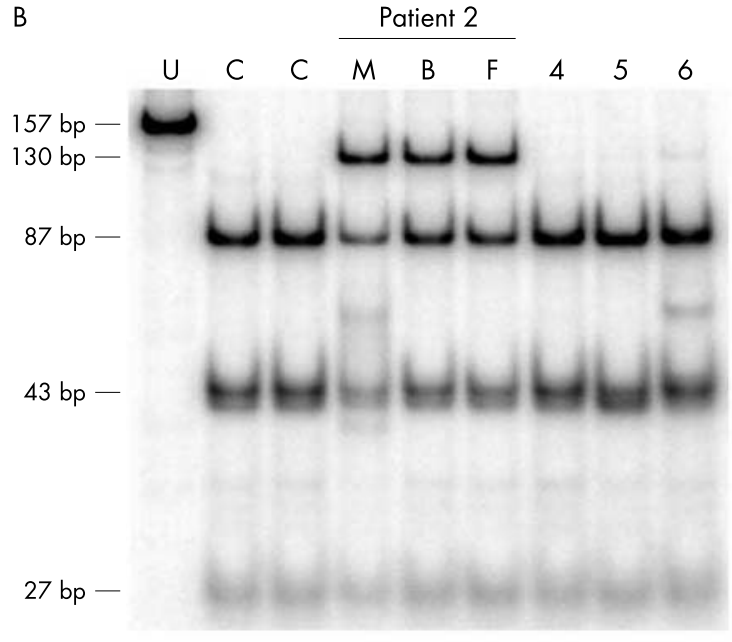

C

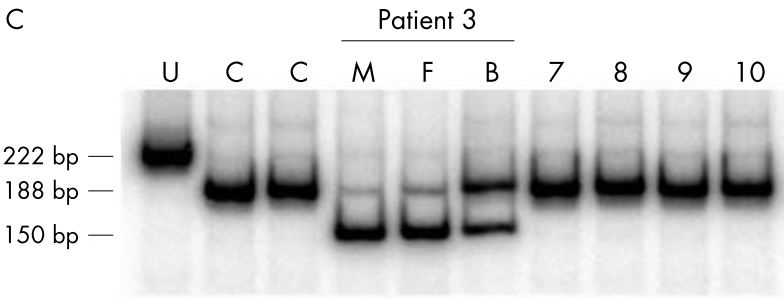

Figure 1 Quantification of the level of mutated mtDNA in patients and other relatives by PCR-RFLP analysis. Details of the oligonucleotide primers, restriction endonucleases and expected digestion products are given in table 1. (A) Patient $1(3697 \mathrm{G} \rightarrow \mathrm{A})$; (B) patient $2(3946 \mathrm{G} \rightarrow \mathrm{A})$; (C) patient 3, (3949T $\rightarrow C$ ). U, uncut sample; $C$, control; $M$, skeletal muscle; F, fibroblasts; B, blood. Lanes $1-3$ show blood from the mother and two sisters of patient 1 ; lanes $4-6$ show blood and urinary sediment from the mother and urinary sediment from the sister of patient 2; lanes 7-10 show blood taken from the mother, father, and two brothers of patient 3.

complex II observed in muscle from patients 1 and 3 is entirely consistent with the mitochondrial proliferation noted in their muscle biopsies, a frequent histological finding in many mtDNA disorders.

Sequencing revealed a different novel mutation in the MTNDl subunit gene of each patient. These mutations were heteroplasmic in skeletal muscle and cultured skin fibroblasts, where the mutant load also correlated with the complex I defect. Patient 2 had a somewhat lower mutant load (60\% in muscle and $45 \%$ in fibroblasts), but this is not without precedent in complex I genes, as comparably low mutant loads of the $13513 \mathrm{G} \rightarrow \mathrm{A} \quad($ MTND5) have been

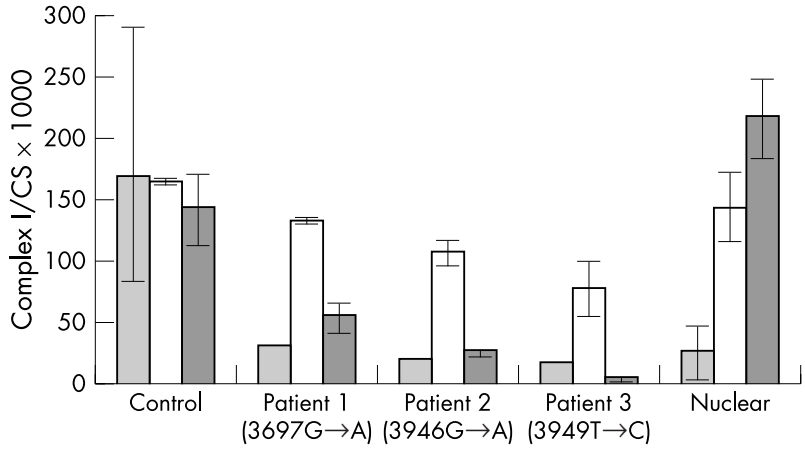

Figure 2 Complex I activity (expressed relative to citrate synthase; CS) in patient cell lines and hybrids. The light grey columns show complex I activity in transformed fibroblasts. Open bars show complex I activity in hybrids between control transformed fibroblasts and transformed fibroblasts from either a control, patient 1, 2, 3, or a patient from a consanguineous pedigree with a presumed nuclear DNA mutation. Dark grey columns show complex I activity in hybrids between the 143BTK $\rho^{0}$ osteosarcoma cell line and the control or patient cell lines. The error bars represent the observed range for all complex I measurements for that cell line, which were as follows: control transformed fibroblast cell line $(n=23)$; parental transformed fibroblasts from patients 1,2 , and 3 $(n=1)$; "nuclear" patient transformed fibroblasts $(n=8)$; patient $1 \times \rho^{0}$ hybrid $(n=4)$; and all other fusions (both with control and $\rho^{0}$ cell lines) $(n=2)$.

associated with Leigh disease. ${ }^{14}$ The mutations were not present in three large mtDNA sequence databases (see Results) nor were they present in 68 complex I deficient children in whom no causative mutations had been identified. Pathogenicity was confirmed by the failure to restore complex I activity upon fusion of fibroblasts with a cell line $\left(\rho^{0}\right)$ containing no mtDNA (fig 2). In these circumstances, patient mitochondria are observed in a different nuclear background and rescue of the biochemical defect is therefore evidence of a nuclear origin for the complex I deficiency. ${ }^{19} 20$

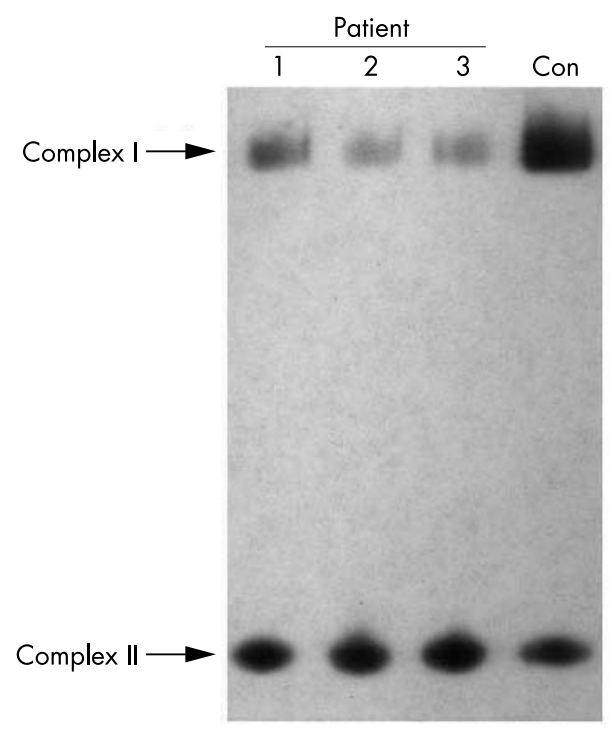

Figure 3 Analysis of levels of assembled complex I by BN-PAGE. Mitochondria isolated from patient fibroblasts and a control (Con) were solubilised in dodecyl maltoside and subjected to BN-PAGE and subsequent Western blot analysis using antibodies specific for the complex I $39 \mathrm{kDa}$ subunit and complex II $70 \mathrm{kDa}$ subunit. The amount of fully assembled complex I relative to complex II was estimated by densitometry of the BN-PAGE immunoblot and shown to be $25 \%$ for patient $1,11 \%$ for patient 2 , and $12 \%$ for patient 3 . 


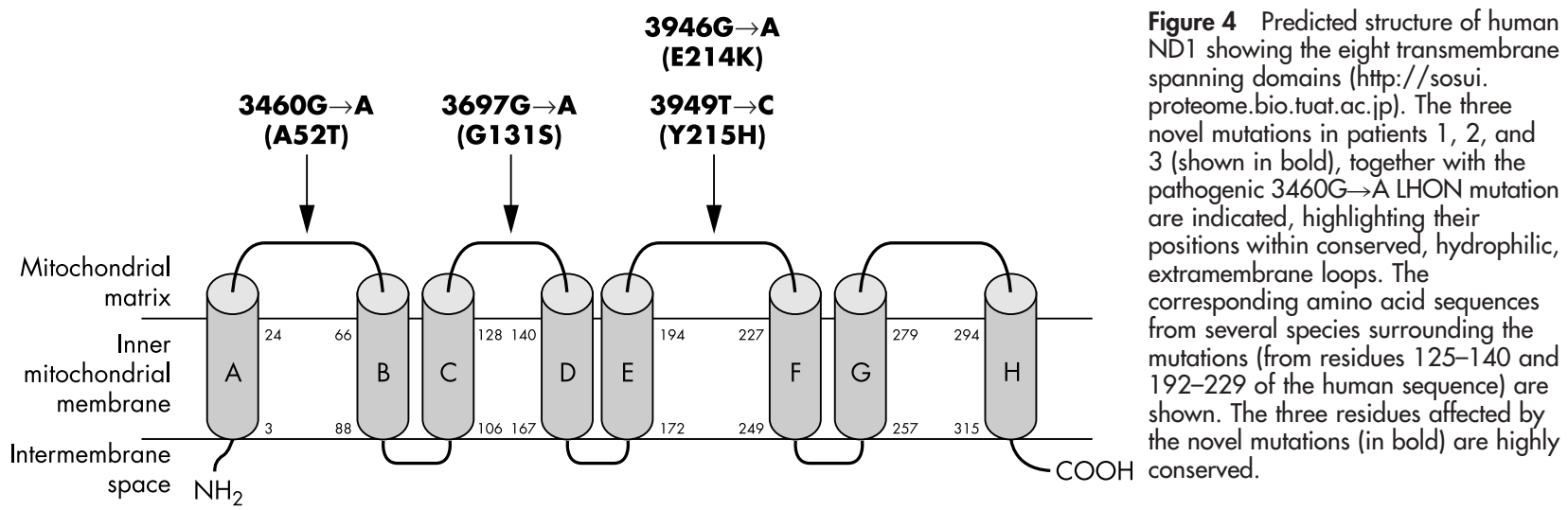

Figure 4 Predicted structure of human ND1 showing the eight transmembrane proteome.bio.tuat.ac.jp). The three 3 (shown in 1 ) pathogenic $3460 \mathrm{G} \rightarrow \mathrm{A}$ LHON mutation are indicated, highlighting their

positions within conserved, hydrophilic, extramembrane loops. The corresponding amino acid sequences from several species surrounding the 192-229 of the human sequencel are shown. The three residues affected by the novel mutations (in bold) are highly space $\mathrm{NH}_{2}$

\begin{tabular}{|c|c|c|}
\hline & 131 & $214 \quad 215$ \\
\hline Homo sapiens & NSNYALIGALRAVAQTI & TNRTPFDLAEGESELVSGFNIEYAAGPFALFFMAEYT \\
\hline Mus musculus & NSKYSLFGALRAVAQTI & TNRAPFDLTEGESELVSGFNVEYAAGPFALFFMAEYT \\
\hline Gallus gallus & NSNYALLGSLRSVAQTI & TNRAPFDLTEGESELVSGFNVEYAAGPFAMFFLAEYA \\
\hline Xenopus laevus & NSKYALIGALR & TNRAPFDLTEGESELVSGFNVEYAAGPFALFFMAEYT \\
\hline Drosophila melanogaster & KSKYGMVGAIRASSQSV & LNRAPFDFAEGESELVSGYNVEYSSVAFVLLFLGEYG \\
\hline Ies gambiae & NSNYALLGGLRAVAQTI & TNRTPFDFAEGESELVSGFNVEYSSGGFALIFLAEYS \\
\hline Caenorhabditis elegans & KSKYGMIGAIRASSQSI & LNRAPFDFSEGERELVRGFNVEYARVAFVLLFLSEYG \\
\hline Paracoccus denitrificans & NSKYPFLASLRSAAQMI & CNRPPFDLVEAESELVAGFMTEYSSTPYLLFMAGEYI \\
\hline Rhoc & NSKYPFLGSLRS & TNRPPFDLPEAESELVAGFMVEYSSTPYLLFMAGEYI \\
\hline ichia coli & NNKYSLLGAMRASAQTL & CHRHPFDQPEAEQELADGYHIEYSGMKFGLFFMGEYI \\
\hline Chlamydomonas reinhardtii & NSKYAFLGCLRSVALMV & TKRDPFDLP--EAELVAGYNVEYSSLGF-ALFFIAEY \\
\hline
\end{tabular}

At present, there is only one mutation in the MTNDI gene with compelling evidence for pathogenicity, 3460G $\rightarrow$ A, which is thought to cause LHON. ${ }^{7-9}$ We believe the novel mutations described here represent three further pathogenic mutations in MTND1. Firstly, they all change conserved amino acids of complex I and are associated with complex I deficiency in patient tissues and in $\rho^{0}$ hybrids. Secondly, they are heteroplasmic, with much higher levels of the mutation present in patient tissues than in unaffected relatives. Finally, they are absent both in large numbers of controls and in asymptomatic maternal relatives of the probands.

NDl is one of the most conserved complex I subunits. ${ }^{21}$ Situated in the hydrophobic arm of the L shaped complex I protein, it forms eight transmembrane spanning domains that are postulated to be involved in ubiquinone binding and proton pumping, ${ }^{22}$ processes known to be disrupted by mutations in homologous bacterial genes. Specific impairment of ubiquinone reductase activity has been demonstrated following mutation of the nqo8 gene (homologous with human NDI) of Paracoccus denitrificans. ${ }^{23}$ Furthermore, studies of the NQO8 subunit suggest that glutamate residues located close to helices $\mathrm{E}$ and $\mathrm{F}$ on the matrix side of the mitochondria are involved in quinone binding and reduction. ${ }^{24}$ In Rhodobacter capsulatus, the NDl homologue NUOH and the NUOD subunit, which is the homologue of the nuclear encoded $49 \mathrm{kD}$ subunit of complex I in mitochondria, also appear to be involved in ubiquinone binding. ${ }^{25}$ Interestingly, the three novel mutations reported here, in common with mutations described in bacterial homologues of MTNDI and the LHON mutation 3460G $\rightarrow$ A, also cause an amino acid change in the hydrophilic loops that face the mitochondrial matrix (fig 4). The $3697 \mathrm{G} \rightarrow \mathrm{A}$ (G131S) mutation in patient 1 occurs at a highly conserved residue in the loop between transmembrane domains C and D. ${ }^{21} 26$ The $3946 \mathrm{G} \rightarrow \mathrm{A}(\mathrm{E} 214 \mathrm{~K})$ and $3949 \mathrm{~T} \rightarrow \mathrm{C}(\mathrm{Y} 215 \mathrm{H})$ mutations in patients 2 and 3 are in the glutamic acid rich hydrophilic loop between transmembrane domains $\mathrm{E}$ and $\mathrm{F}$, one of the most conserved regions of the NDl subunit. ${ }^{2126}$ The mutations in patients 2 and 3 change the charge of the amino acid and are both predicted to abolish a $\beta$ turn in the NDl protein. ${ }^{27}$
At the protein level, the mutations in our MELAS patients appear to affect complex I assembly or turnover (fig 3). The BN-PAGE results demonstrate low levels of fully assembled complex I in fibroblasts from the three patients, with the $3946 \mathrm{G} \rightarrow \mathrm{A} \quad(\mathrm{E} 214 \mathrm{~K})$ and $3949 \mathrm{~T} \rightarrow \mathrm{C} \quad(\mathrm{Y} 215 \mathrm{H})$ mutations in patients 2 and 3 appearing to be more detrimental. The NDl subunit is thought to be incorporated into the complex I structure at an early stage of its assembly. ${ }^{10}$ This implies that the decreased levels of fully assembled complex I are due to impaired assembly of complex I, with consequent degradation of unincorporated subunits. A similar mechanism has been demonstrated for the cytochrome c oxidase subunits in patients with mutations in SURF1. ${ }^{28}$

It is interesting to note that all three patients with MTNDI mutations expressed a complex I defect in cultured fibroblasts. Similarly, we found that all of eight patients with mutations in the MTND $3,{ }^{15} M T N D 5,{ }^{14}$ and MTND $6^{29}$ subunit genes who presented with Leigh disease or other infantile encephalopathies also expressed complex I deficiency in fibroblasts. By contrast, our experience with five patients with complex I deficiency caused by mutations in MTTLI (two with 3243A $\rightarrow \mathrm{G}$ and one each with 3250T $\rightarrow \mathrm{C}$, 3303C $\rightarrow \mathrm{T}$, and $3242 \mathrm{G}>\mathrm{A})^{2}$ is that all but the $3242 \mathrm{G}>\mathrm{A}$ patient had low mutant loads and normal complex I activity in fibroblasts (results not shown). Thus patients with mutations in MTND subunit genes express a complex I defect in fibroblasts more often than those with MTTL1 mutations.

Liolitsa et al have proposed that the MTNDS gene is a hot spot for mutations causing MELAS, and note four mutations in this gene that have been associated with the syndrome: $13513 \mathrm{G} \rightarrow \mathrm{A}, \quad 13514 \mathrm{~A} \rightarrow \mathrm{G}, \quad 12770 \mathrm{G} \rightarrow \mathrm{A}, \quad$ and $\quad 13045 \mathrm{~A} \rightarrow \mathrm{C} .^{5}$ Certainly, it would appear that the aetiology of MELAS is diverse and that following exclusion of the $3243 \mathrm{~A} \rightarrow \mathrm{G}$ mutation, a targeted sequencing approach should be directed by the results of muscle biochemistry. In patients with MELAS, isolated complex I deficiency has proved an important indicator of a MTND gene mutation and our finding of three novel mutations in three unrelated patients suggests that the MTNDI gene may also be a hot spot for mutations that cause this devastating disease. 


\section{ACKNOWLEDGEMENTS}

This work was supported by grants from the National Health and Medical Research Council of Australia, the Australian Research Council, the Muscular Dystrophy Association of the USA, the Wellcome Trust, the Muscular Dystrophy Campaign UK and the Newcastle upon Tyne Hospitals NHS Trust. R McFarland is an MRC Clinician Scientist and D R Thorburn is an NHMRC Senior Research Fellow.

\section{Authors' affiliations}

D M Kirby, D R Thorburn, Murdoch Childrens Research Institute, Royal Children's Hospital, Melbourne, Australia

D M Kirby, D R Thorburn, Genetic Health Services Victoria, Royal Children's Hospital, Melbourne, Australia

D M Kirby, D R Thorburn, Department of Paediatrics, University of Melbourne, Australia

R McFarland, D M Turnbull, R W Taylor, Mitochondrial Research

Group, School of Neurology, Neurobiology and Psychiatry, University of Newcastle upon Tyne, UK

A Ohtake, C Dunning, M T Ryan, Department of Biochemistry, La Trobe University, Melbourne, Australia

A Ohtake, Department of Paediatrics, Saitama Medical School,

Moroyama, Saitama, Japan

C Wilson, Metabolic Service, National Testing Centre, Starship

Children's Hospital, Auckland, New Zealand

D Ketteridge, Department of Chemical Pathology, Women's and

Children's Hospital, Adelaide, Australia

Conflicts of interest: none declared

Correspondence to: Dr R W Taylor, Mitochondrial Research Group, School of Neurology, Neurobiology and Psychiatry, University of Newcastle upon Tyne, Newcastle upon Tyne NE2 4HH, UK; r.w.taylor@ ncl.ac.uk

Received 12 March 2004

Revised 6 April 2004

Accepted 8 April 2004

\section{REFERENCES}

1 Robinson BH, De Meirleir L, Glerum M, Sherwood G, Becker L. Clinical presentation of mitochondrial respiratory chain defects in NADH-coenzyme $Q$ reductase and cytochrome oxidase: clues to pathogenesis of Leigh disease. J Pediatr 1987; 110:216-22.

2 Kirby DM, Crawford M, Cleary MA, Dahl HH, Dennett X, Thorburn DR. Respiratory chain complex I deficiency: an underdiagnosed energy generation disorder. Neurology 1999;52:1255-64.

3 Loeffen JL, Smeitink JA, Triibels JM, Janssen AJ, Triepels RH, Sengers RC, van den Heuvel LP. Isolated complex I deficiency in children: clinical, biochemical and genetic aspects. Hum Mutat 2000;15:123-34.

4 DiMauro S, Schon EA. Mitochondrial respiratory-chain diseases. NEngl J Med 2003;348:2656-68

5 Liolitsa D, Rahman S, Benton S, Carr $\sqcup$, Hanna MG. Is the mitochondrial complex I ND5 gene a hot-spot for MELAS causing mutations? Ann Neurol 2003;53:128-32.

6 Ravn K, Wibrand F, Hansen FJ, Horn N, Rosenberg T, Schwartz M. An mtDNA mutation, $14453 \mathrm{G} \rightarrow \mathrm{A}$, in the NADH dehydrogenase subunit 6 associated with severe MELAS syndrome. Eur J Hum Genet 2001;9:805-9.

7 Huoponen K, Vilkki J, Aula P, Nikoskelainen EK, Savontaus ML. A new mtDNA mutation associated with Leber hereditary optic neuroretinopathy. Am J Hum Genet 1991;48:1147-53.

8 Majander A, Huoponen K, Savontaus ML, Nikoskelainen E, Wikstrom M. Electron transfer properties of NADH-ubiquinone reductase in the NDI/
3460 and the ND4/11778 mutations of the Leber hereditary optic neuroretinopathy (LHON). FEBS Lett 1991;292:289-92.

9 Howell N, Bindoff LA, McCullough DA, Kubacka I, Poulton J, Mackey D, Taylor L, Turnbull DM. Leber hereditary optic neuropathy: identification of the same mitochondrial ND1 mutation in six pedigrees. Am J Hum Genet 1991;49:939-50.

10 Antonicka H, Ogilvie I, Taivassalo T, Anitori RP, Haller RG, Vissing J, Kennaway NG, Shoubridge EA. Identification and characterization of a common set of complex I assembly intermediates in mitochondria from patients with complex I deficiency. J Biol Chem 2003;278:43081-8.

11 Rahman S, Blok RB, Dahl HHM, Danks DM, Kirby DM, Chow CW, Christodoulou J, Thorburn DR. Leigh syndrome: clinical features and biochemical and DNA abnormalities. Ann Neurol 1996;39:343-51.

12 Taylor RW, Taylor GA, Durham SE, Turnbull DM. The determination of complete human mitochondrial DNA sequences in single cells: implications for the study of somatic mitochondrial DNA point mutations. Nucleic Acids Res 2001;29:E74-4.

13 Andrews RM, Kubacka I, Chinnery PF, Lightowlers RN, Turnbull DM, Howell N. Reanalysis and revision of the Cambridge reference sequence for human mitochondrial DNA. Nat Genet 1999:23:147.

14 Kirby DM, Boneh A, Chow CW, Ohtake A, Ryan MT, Thyagarajan D, Thorburn DR. Low mutant load of mitochondrial DNA G13513A mutation can cause Leigh's disease. Ann Neurol 2003;54:473-8.

15 McFarland R, Kirby DM, Fowler KJ, Ohtake A, Ryan MT, Amor DJ, Fletcher JM, Dixon JW, Collins FA, Turnbull DM, Taylor RW, Thorburn DR. De novo mutations in the mitochondrial ND3 gene as a cause of infantile mitochondrial encephalopathy and complex I deficiency. Ann Neurol 2004;55:58-64.

16 MITOMAP: A Human Mitochondrial Genome Database. http:// www.mitomap.org, 2004

17 MitoKor. http://www.mitokor.com/science/560mtdnas.php.

18 Rahman S, Poulton J, Marchington D, Suomalainen A. Decrease of 3243 $A \rightarrow G$ mtDNA mutation from blood in MELAS syndrome: a longitudinal study. Am J Hum Genet 2001;68:238-40.

19 Munaro M, Tiranti V, Sandona D, Lamantea E, Uziel G, Bisson R, Zeviani M. A single cell complementation class is common to several cases of cytochrome c oxidase-defective Leigh's syndrome. Hum Mol Genet 1997;6:221-8.

20 Procaccio V, Mousson B, Beugnot R, Duborjal H, Feillet F, Putet G, PignotPaintrand I, Lombes A, De Coo R, Smeets H, Lunardi J, Issartel JP. Nuclear DNA origin of mitochondrial complex I deficiency in fatal infantile lactic acidosis evidenced by transnuclear complementation of cultured fibroblasts. J Clin Invest 1999;104:83-92.

21 Fearnley IM, Walker JE. Conservation of sequences of subunits of mitochondrial complex-I and their relationships with other proteins. Biochim Biophys Acta 1992;1140:105-34.

22 Fisher N, Rich PR. A motif for quinone binding sites in respiratory and photosynthetic systems. J Mol Biol 2000;296:1153-62.

23 Zickermann V, Barquera B, Wikstrom M, Finel M. Analysis of the pathogenic human mitochondrial mutation ND1/3460, and mutations of strictly conserved residues in its vicinity, using the bacterium Paracoccus denitrificans. Biochemistry 1998;37:11792-6.

24 Kurki S, Zickermann V, Kervinen M, Hassinen I, Finel M. Mutagenesis of three conserved Glu residues in a bacterial homologue of the NDI subunit of complex I affects ubiquinone reduction kinetics but not inhibition by dicyclohexylcarbodiimide. Biochemistry 2000;39:13496-502.

25 Darrouzet E, Issartel JP, Lunardi J, Dupuis A. The 49-kDa subunit of $\mathrm{NADH}$-ubiquinone oxidoreductase (complex I) is involved in the binding of piericidin and rotenone, two quinone-related inhibitors. FEBS Lett 1998;431:34-8.

26 Roth R, Hagerhall C. Transmembrane orientation and topology of the $\mathrm{NADH}$ :quinone oxidoreductase putative quinone binding subunit $\mathrm{NuoH}$. Biochim Biophys Acta 2001;1504:352-62.

27 Combet C, Blanchet C, Geourjon C, Deleage G. NPS@: network protein sequence analysis. Trends Biochem Sci 2000;25:147-50.

28 Yao J, Shoubridge EA. Expression and functional analysis of SURF1 in Leigh syndrome patients with cytochrome c oxidase deficiency. Hum Mol Genet 1999;8:2541-9.

29 Kirby DM, Kahler SG, Freckmann ML, Reddihough D, Thorburn DR. Leigh disease caused by the mitochondrial DNA G14459A mutation in unrelated families. Ann Neurol 2000;48:102-4. 